\title{
MEMÓRIA FAMILIAR NOS OBJETOS BIOGRÁFICOS E NAS OBRAS LITERÁRIAS
}

Clêidna de Lima'

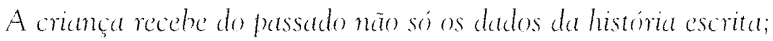
mergulha suas raizes na história vinida, ou melhom; sobrevivida, das pessoas de

idade aue tomaram parte na sua socialização. Sem estas haveria apenas uma competência abstrata para lidar com os dados do passado mas näo a memória.

(BOSI, 1994, p.73)

RESUMO:

Neste artigo pretende-se refletir sobre a leitura e releitura de ohjetos biográficos, relíquias de família e as histórias que estes objetos trazem em forma de lembrança, valores repassados de uma geração à outra. Busca-se ainda explorar a presença desses objetos e memórias em obras literárias que favoreçam esta releitura com alunos do ensino fundamental.

UNITERMOS: Objetess Bingráficos, Relíquias de familia, Memória Literária.

Foi dado o sinal. Início de aula. Alguns alunos ainda chegam, outros, já sentados em dupla, conversam entre si. Além dos objetos comuns à uma sala de aula (mesas, cadeiras, quadrosgiz, apagador) outros fazem parte deste espaço. O rol destes oljetos é variado: ferros à brasa, secador de cahelos, coleçñes de dinheiro, uma caneca, um macacão jeans, um crucifixo, uma bengala de madeira, um espelho caneta, um jogo de talheres,

\footnotetext{
I Professora do Centro de Ensino e Pesquisa Aplicada à Educação (CEPAE) da Universidade Federal de Goiás-UFG. Especialista em Educação pré-escolar e integrante do Grupo Gwaya-Contadores de histórias/UFG.
} 
uma escova para tirar o pó das roupas, uma coruja de porcelana, uma moeda de prata, uma pedra de ouro (o chamado ouro de tolo), um relógio de pêndulo cuco, um porta batons, uma harpa, fotos de álbum de família...

Tudo indica que estes objetos apreciados individualmente já foram "apresentados" aos vizinhos de mesa e muitos demonstram ansiedade em falar do assunto, ao grupão, ou quem sabe ouvir, matar algumas curiosidades e depois voltar à sua relíquia. Este é só um início de aula.

Por época das reflexões suscitadas pelos 500 anos do Brasil convidei um grupo de alunos de $3^{a}$ série à buscarem em suas casas um objeto com a "cara" de sua família. Relíquias de família começaram a chegar à escola trazidas com emoção bem presas por dedinhos orgulhosos, como a dizerem: - aqui estamos nós!

Acompanhando cada objeto uma descrição feita por um membro da família, outra pelo(a) aluno(a) e a data provável de posse do objeto, há quanto tempo ele está na mesma família como fonte histórica e o por quê de estar a tanto tempo avivando as lembranças daquela mesma família.

Até ayuele momento, ainda, não havíamos compartilhado de histórias como esta:

aupele porta canetas significa que meu pai gosta muito de mim porcue ele ganhou no Pré e cle disse: Eu vou guardar para o meu filho porque euvou mostrar para ele que eu vou gostar muito dele; Eeu vou guardar para cuando en tiver um filho ou tilha para ela guardar para o filho ou fillha dele, mas se na escola eles quebrarem até eu vou ficar com triste. (Alex -9 anos)

\footnotetext{
- Os nomes de pais a alunos sáto fictícios; os textos escritos como se apresentam nos originais.
} 
Parece inimaginável que o pai de Alex, já no prezinho, planejasse sua vida familiar com tantos detalhes, mas a releitura que ambos fazem deste passado de mais ou menos meio século além de ser uma promessa de amor paternal apontam para os valores que esta família tem vivenciado e pretende reviver $\mathrm{com}$ as próximas gerações. De acordo com E. P. Trompson

é a experiência humana - "termo médio entre o ser social e a consciência social", que tinge a cultura e cria padrões de valores sociais, assim como é a prática que constrói o mundo das diferenças a das necessidades materiais : Os valores "são vividos". (MALUF, 1995)

Quando Alex conclui: "Aquele porta canetas significa que meu pai gosta muito de mim [...]"; parece estar repetindo uma frase muitas vezes ouvida; como afirma Bosi (1994), "Todos os acontecimentos de fora chegam até a criança filtrados e interpretados pelos parentes. Hoje impõe como mediação também os meios de comunicação". Assim também nos parece quando a personagem de A Mãe de Mãe da Minha Mãe $e^{3}$ quando refaz os passos de seu primeiro encontro com sua bisavó. Vai entrando na casa da bisavó através das portas superpostas, vazadas nas páginas dos livros, até chegar ao jardim:

Eu tiuha cinco anos, Bivómandou me chamar. Vestiram-me com vestido de presente. Não sei se me lembro, mas era amarelo com bordados. Calcinha tricotada pela vovó, fillha da Bivó. Bivó morava num sobrado do outro lado da rua da vovó, quando eu tinha cinco anos. Eu estava de visita na casa da filla da Bivó. [...] Cheguei na porta do sobrado. Uma escada de cem metros para subir e uma ladainha com minha mãe e minha vó, cantando: segura no corrimão, cuidado, cair quebra a perna, não suja a roupa, deixa o Totó no chão [...] (ALVAREN(iA, 1999, p. 1).

'AlVARENGA, Terezinha. A Mäe de Mäe da Minha Mäe1. 5. ed. Miguilim, 1999. 
Detalhes de um momento marcante, lapidados pelo tempo, estão repletos das impressões de todos que o recontaram até o momento presente com olhos e elaborações atuais.

Perguntas estão no ar: Que histórias lembram cada objeto aparentemente sem atrativos? O fio invisível da memória individual tece a memória coletiva ou vice-versa? Para Halbwachs

memória individual é um ponto de vista da memória coletiva, e esse ponto de vista varia de acordo como lugar social que é ocupado; este lugara, por sua vez, muda em função das relaçñes que se tem com outros meios sociais (BARROS, 1989, p. 31).

Segundo Benjamin, existe uma dimensão da vida que lentamente a "modernidade" vai anulando. Um trecho de seu texto "Experiência e Pobreza", simboliza aquela época:

Sabia-se exatamente o significado da experiência: ela sempre fora comunicada aus jovens. De forma concisa, com a autoridade da velhice, em provérbios: de forma prolixa, com a sua locytacidade, em histórias; muitas vezes como narrativas de países longínquos, diante da lareira, contadias a pais e netos.

Que foi feito de tudo isso? Quem encontra ainda pessoas que saiban contar histórias como elas devem ser contadas? Que moribundos dizem hoje palavras tão duráveis que possam ser transmitidas como um anel, de geração) em geração? Quem é ajudado, hoje por um provérbio oportuno? Q Quem tentará, sequer, lidar com a juventude invocando sua experiência? (BENJAMIN, 1985, p. 115)

\footnotetext{
+ Nesse sentido, a imagen de nossa modemidade resgatada por Berman, que, inspirando-se em Marx, diz yue "tudo que é sólido desmancha no ar", coloca mossal memória em face de netamorfoses radicais. (BERMAN, M.; MOISES, C. F; IORIATTI, A. M. L. Tudo que é sólido desmancha no ar. Säo Paulo: Companhia das Letras, 1987.)
} 
Dentre os objetos trazidos houve uma predominância dos que pertenciam ao bisavô e à bisavó, herdados por avós e pais, estão agora burilando histórias das crianças na sala de aula...

Não são apenas os retratos antigos dos avós, tios, primos, pais, e irmãos que têm a função de relembrar a união familiar mas também móveis e objetos. São símbolos da família, laços de descendência.

Talvez ahrindo e fechando os álbuns de família se esteja também num abrir e fechar de olhos que vai tirando fotos da memória:

Esta outra foto mostra eu Isis e meu pai Mauro e minha mãe Lia. Eu estou com cinco dias de vida. Dia 22/05/91 foi tirada a foto. Aniv. $17 /$ 05/91. Estas fotos são muito especiais. (Isis - aluna).

A foto n 1 mostra a minha sogra, O. M. S., à época em que ela tinha apenas cinco anos de idade. Uma fotografia rara em nosso állum familiar. E, por isto mesmo, de grande valor histórico e afetivo. (Mauro-pai de Isis).

Organizar gavetas e álbuns repletos de imagens equivale ao trabalho de um pesquisador pois remete-nos às idéias de trabalho, ansiedade, cansaço e culpa. É momento de escolha das imagens que irão narrar as histórias da família: "[...] naquela confusão de tempos e memórias, uma narrativa com uma linguagem clara" (BARROS, 1989, p. 38).

Quando buscamos luzes que iluminem a nossa infância e que tragam imagens de nossa casa, não buscamos só aquilo que as Instituições "socalizadoras" (escola, igreja, pais) nos ensinaram, não buscamos só o escrito. Buscamos o que foi dito, ouvido os sons das vozes que ecoam em nossa memória; em nossas recordações estão pessoas, $\mathrm{com}$ as quais convivemos em situações onde ouvimos frases como: "No meu tempo [...] quando eu era do seu tamanho $[\ldots]$ cuuando você crescer $[\ldots]$ ". Nestas situações 
o tempo que conta é passado e futuro. Aos avós, por exemplo, não cabe a tarefa definida da educação dos netos. E assim nas reminiscências da infância de cada um encontramos a presença da "socialização dos peyuenos".

Neste aspecto nossas idéias sintonizam-se com Ecléa Bosi (1994, p. 74):

É graças a esta "outra socialização" que não estranhamos as regiões sociais do passado: ruas, casas, móveis, roupas antigas, histórias maneira de falar e de se comportar em outros tempos. Não só não nos causam estranheza, como, devido ao íntimo contato com nossos avós nos parecem singularmente familiares. Singularidade que pode estar presente em relatos assim:

[...] um ferro à brasa [...] ele foi usado para passar o vestido de casamento da minha vó paterna [...] eléé muito importante para minha família. (Ciro - 9 anos)

Eu vivia falando à minha mãe, porque ela aceitou o prato ? Ela disse poryue ele marcou a vida da avó e da mãe dela e dela e hoje o prato vive lá em casa. (Isa-9 anos)

Quantas experiências vividas estão possivelmente representadas em cada objeto destes pequenos recordadores, que repetem histórias ouvidas de seus familiares? Se adentrássemos na casa de onde saíram, estaríamos conhecendo as aventuras afetivas de seus moradores.

Um menino viu-se magoado, embravecido mesmo, ao ouvir alguns outros dizerem que uma caneca trazida por ele havia sido adquirida em loja de artigos à $R \$ 1,99$. Aquela caneca, não! Não aquela que o pai comprara para a avó patema quando menino como ele. Comprara com dinheiro "suado", conquistado com venda de picolés e jornais para presentear em un dia das mães... "ayuela caneca" era muito mais valiosa! A avó paterna devolvera ao pai de nosso pequeno de hoje, para que "um dia" pudesse mostrar aos filhos "que teria". 


\section{O) pai relata o seguinte:}

Fui criança criada com muitas dificuldades financeiras. Para acompanhar as demais crianças nos passeios e demais necessidades da idade, eu tinha que trabalhar. Nos dias de semana eu vendia jornais e picolés nas ruas do bairro de Campinas, onde fui criado. Nos finais de semana eu trabalhava com carrinho de fretes nas feiras livres, carregando as sacolas das senhoras, as melancias, as hananas, as compras em geral. Meus colegas, filhos de pais que tinham melhores condições que os meus, viviam passeando no zoológico, no cinema, nos clubes e nas lanchonetes e eu, como menino esperto que sempre fui, traballhava para poder acompanhálos. Certo mês de maio de um ano que não me lembro, mas faz muito tempo, meus colegas compravam presentes para suas mães com o dinheiro que os pais davam. Eu como sempre tive que "me virar" para comprar um presentinho para mamãe, pois não ia deixar uma data dessa passar em branco. Com un dinheirinho que ganhei na semana, fui em uma loja de utilidades domésticas e comprei $u$ m copo bordado e muito bonito para dar para a mamãe. Não era um presente tão hom quanto os dos meus colegas, porém era fruto do meu trabalho e isso é que importava. Ficuei muito feliz ao dar o presente para a mamãe pois ela ficou muito orgulhosa de ter um filho e que sempre lembrava dela. Foi um dia das mães inesquecível e o copo que dei a ela, foi me presenteado de volta quando me casei e hoje mostro orgulhoso para meus filhos tentando passar a cles o exemplo de dedicação e carinho que me acompanha desde criança. Espero cue a lição sirva também para os colegas de meus filloss. (Antônios - pai de aluno)

Acpuele copo/caneca já não era mais um objeto de consumo mas um "suporte" para lembranças daquela família.

Para Bosi (1994) os suportes materiais da memória vão sendo destruídos pela sociedade capitalista que bloqueia os caminhos da lembrança, arranca seus marcos e apaga seus rastros. A

\footnotetext{
Texto dedicado a seus três filhos e intitulado Dia das Mães.
} 
memória das sociedades antigas apoiavam-se em "valores ligados à práxis coletiva como a vizinhança (versus mobilidade), a família numerosa (acrsus Ilhamento da família restrita), apego a certas coisas a certos objetos biográficos (versus objeto de consumo)... eis aí alguns arrimos em que a memória sempre se apoiou.

Roseana Murray" (1994)nos fala de herança familiar com olhos cor de emoção:

A família toda ficava de olho no casarão. Estava caindo os pedaços, mas o terreno era muito valioso. Com o dinheiro da venda da casa poderiam comprar tantas coisas. Os olhos da família até mudava de cor, ficavam de cor de cobiça. Só tinha uma coisinha que atrapalhava. Uma coisa bem pequena, uma bobagem cue logo seria resolvida. Dentro do casarão moravam três tias, tão velhinhas tão velhinhas. A família se reunia, discutia, voltava a se reunir (MURRAY, 1994, p. 2).

Se continuamos a folhear Três Tias Tão Velhinhas, Tão Velhinhas; vamos confirmando o que a casa é mais que terreno muito valioso, pode ser espaço de vivências. A maior parte das lembranças só é guardada graças à casa e, muitas vezes, à custa de fragmentos, objetos, sons e odores, uma infinidade de detalhes que funcionam como verdadeiros "arrimos de memória":

Maria a mais séria das três, pensava nas coisas sérias da vida. Enquanto Clara compunha canções antigas a Matilde inventava plantas, ela pensava pequenos pensamentos simples e sérios. Por exemplo, um dia teriam que ir embora desse mundo. O coração já estava ficando cansado. E o que seria do casarão? Com certeza a familia venderia. Com tudo que tinha dentro. As lembranças os anos vividos, os sonhos. E demoliriam o casarão, e tudo seria demolido junto. Os sonhos, os anos vividos, as lembranças. Maria ficava triste com estes pensamentos sérios (MURRAY, 1994, p. 8).

"MURRAY, Roseana. Três tias tão velhinhas, tão Velhinhas. Miguilim, 1994. 
Tanto os recordadores da escola, das famílias e personagens de obras literárias têm como suportes materiais para suas lembranças as casa em que viveram, objetos comuns, de uso cotidiano carregados de significações afetivas; nenhum deles fala de objetos que a moda valoriza ou do valor monetário do objeto que elegeram como símbolo familiar. Ao rememorar e reconstruir a casa da infância ou de outro período vivido cada um determina dentro de um espaço recriado, o lugar dos objetos e das ações que os acompanham. Provando que a memória coletiva também classifica e seleciona aquilo que quer ou não rememorar. Segundo Halbwachas, "[...] O indivíduo ao se comportar como membro de um grupo, contribui para evocar as lembranças que o grupo conseguiu selecionar."

As coisas nos falam numa comunicação silenciosa que marca nossas relações mais profundas:

Não só em nossa sociedade dividimos as coisas em objetos de consumo e relíquias de família. Mauss encontra essa distinção $\mathrm{em}$ muitos poros: tanto entre os romanos como entre os povos de Samoa e Trobriand e os indígenas norte americanos. Há objetos como os talismãs, cobertas de pele e cobres blasonado, tecidos armoriais que se transmitem solenemente como as mulheres no casamento, os privilégios, os nomes às crianças. Essas propriedades são sagradas, não se vendem, nem são cedidas, e a família jamais se desfaria delas a não ser com grande desgosto. O conjunto dessas coisas em todas as tribos é sempre de natureza espiritual (BOSI, 1994, p. 30).

Violette Morin (apud BOSI, 1994) diferencia os objetos em hiográficos e protocolares conceituando como objetos biográficos os que envelhecem com seu possuidor por representar uma experiência de vida, mais que um sentimento estético ou de utilidade posicionam e identificam o indivíduo no mundo: 
Meu pai escolheu elas porque foi seu pai que te deu, já falecido, cla é de 1937 (73anos) é uma de 400 Réis e 200 Réis a de 400 Réis tem a cara do Osvalde Cruz a de 300 Réis eu não sei. (Marco-9 ancos)

E logo em seguida o pai vem confirmar que as características identificadoras destes objetos é mais que a descrição de exemplares do Sistema Monetário Brasileiro:

Estas moedas são moedas antigas de 400 reis e 200 reis datadas de 1937 eram moedas do meu pai já falecido que ele ganhou do pai dele quando ainda era VIVO. São objetos de estimação que eu ganheida minha mãe após o falecimento do meu pai e que eu guardo com muito carinho, e que não pretendo me desfazer delas por ser algo de muita estima que pertenceu aalguém yque eu amava muito. (Pai de Marco)

Já os objetos protocolures são aqueles que têm garantia do tempo que dura a moda não envelhecem com o dono, se deterioram e são substituíveis.

A mäe de um aluno, que havia trazido uma bengala para a sala de aula, fala de um destes objetos biográficos com toda a simbologia qque aí, literalmente, se apóia:

Esta bengala pertenceu à D. Maria Leles Lopes, uma mineira de St Antônio do Amparo, traballhadora e rezadeira, como as demais senhoras daxpuela épocia. Que época? 1898. É, Há muito tempo atrás. Na verdade, esta bengala yue D). Maria usava tinha sido presente dado por uma de suas fillhas. (om a bengalia, D). Maria Loconovia-se pelocasamento de esymura onde morou sempre, desde que se casou. Apoiando-se nela, l). Maria ia do seu quarto aos demais aposentos. Ia principalmente à copa comer um biscuito bem sequinho com café dece, e também lia para a sala, sentar-se à frente da televisão e fazer o crochê companheiro. Até que un dia a bengala se viu sót!! E foi assim que esta bengala chegou até mim. Cheia de significações e histórias construídas sobre uma vida dedicada ao trabalho e principal-mente, ao amor. 
Sem saber, quieta no seu canto, essa bengala nos apoia também. (Leila-mãe de aluno)

A autora deste texto e recordadora escreve " $[\ldots]$ trabalhadora e rezadeira, como as demais senhoras daquela época. Que época? 1898. É. Há muito tempo atrás." E isto nos suscita alguns questionamentos: As senhoras daquela época eram valorizadas pelo trabalho (doméstico) e pela virtude?. "Que época? 1898. É, Há muito tempo atrás." Ao lermos o ano ficamos em dúvida em função das rasuras. Perfeitamente normal o que menos conta aqui é a data precisa. Falamos de um tempo afetivo ou de outros tempos? Tais indagações nos remetem a curiosa lenda de Ts'ui Pen que se propusera a construir um labirinto infinito e escrever um livro. Todos imaginaram duas obras ninguém imaginou que ambos eram um só objeto. No romance $O$ jardim dos caminhos que se bifurcum, a idéia de tempo mostra mais uma vez que a arte e vida se entrelaçam:

Acreditava-se em infinitas séries de tempos, numa rede crescente e vertiginosa de tempos divergentes e paralelos. Essa trama de tempos que se aproximam, se bifurcam, se cortam ou que secularmente se ignoram, ahrange todas as possibilidades. Não existinos na maioria desses tempos; nalguns existe o senhor e não eu. Noutros, eu não o senhor; noutros, os dois (BORGES, 1989, p. 82).

Nesta experiência de releitura dos objetos trazidos para a escola pode ser que tenha se propiciado momentos em que pais alunos e professores pudessem refazer, reconstruir a trajetória de cada relíquia reconhecendo o caráter não só pessoal, mas familiar, grupal e social da memória.

O pai do meu avô comprou uma fazenda. Nesta fazenda tinha um quarto. No quarto tinha um guarda-roupa. Neste guarda-roupa tinha uma escova! Isso aconteceu ano de 1945. (Joana) 
Esta escova de limpar roupa pertenceu a meu pai e foi adquirida no ano de 1945 juntamente com um guarda -roupas usado. Ela foi feita com crina de cavalo o que justifica sua durabilidade. Eu tenho um carinho muito especial por este objeto e gostava muito de usa-lo. Na época. De sua aquisição eu tinha 13 anos e hoje estou com 67 anos. (Marcos-avô de Joana)

Serão os elos de passado, presente e futuro também elos de sedução para envolvimentos profundos com uma simples tarefa de casa? O avô de Joana fala do pai, "[...] tenho um carinho muito especial por este objeto [...]”, e de como um utilitário doméstico passa a ser relíquia de muitos.

Quantas lembranças foram buriladas, quando o aluno buscava, em sua casa, os objetos significativos para a história de sua família, tão significativos que "lapidados" pelo tempo, hoje, aparecem recriados na sala de aula? Em tempo de nos conhecermos, de ir nos descobrindo... como Bivó que se faz "filha" no afago do primeiro encontro com a bisneta, uma bisneta apavorada por achar ter encontrado, depois de tanta procura, un lobo ou un monstro:

Olhos arregalados, paralisados, mãos grandes, afiadas. A voz rouca me tocava: - lindos... pretos, longos como os de minha mãe...! Que pele de seda rosada, menina! Que vestido bonito de renda e fita, minha netinha...!

Fui ficando mansinha... O Totó latiu. O sorriso foi crescendo das mãos finas, leves, macias. Agora doces. E a corcunda ficou lá atrás... (ALVARENGA, 1999, p. 10)

Ao lermos as descrições, que tornaram-se depoimentos emocionados, parecia yue a vida pulsava mais forte na sala de aula e as vezes parávamos de ler deixando fluírem os pensamentos, emocionados que se refaziam em histórias, constituindo-se como nosso tempo. 


\section{Referências Bibliográficas}

Alvarenga, T. A Mãe da Mãe da Minha Mãe. 15. ed. Miguilim, 1999.

BARROS, M. M. L. de. Memória e Fumília: estudos históricos, Rio de Janciro, v. 2, n. 3, 1989.

BERMAN, M.; MOISES, C. F.; IORIATTI, A. M. L. Tudo que é sólido desmancha no ar. São Paulo: Companhia das Letras, 1987.

BORGES, J. L. O Jardim dos Caminhos que se Bifurcum. 3. ed. São Paulo: Gkobo, 1989.

BOSI, E. Memória e Sociedade : lembrança de velhos. 3. ed. São Paulo: Companhia das Letras, 1994.

HALBWACHS, M. A Memória Coletiva. Rio de Janeiro: Vértice, 1990.

MALUF, M. Ruídos da Memóría. Sãos Paulo: Siciliano, 1995.

MONTENEGRO, A. T. Memórias e História. Série Idéias, 18. O tempo e o Cotidiano na História. São Paulo, 1993.

MURRAY, R. Três Tias Tão Velhinhas, Tão Velhinhas. Miguilim, 1994.

SANTOS, M. S. Revista Brasileira de Ciências Sociais, São Paulo, v. 13, n. 38, out. 1998.

SANTOS, M. S. (Org.). Velhice on Terceira Idede? Estudos antropológicos sobre identidade, memória e política. Rio de Janeiro: Editora Fundação Getúlio Vargas, 1998.

\section{ABSTRACT:}

This paper aims at thinking about reading and re-reading of biographical objects, family's relics and the stories of these objects bring by means of memories as well as by valıes transmitted from generation to generation. It will also exploit the presence of these objects and memories in literary works that support this re-reading with students at the school level.

KEY WORDS: biographical objects, family's relics, literary memories. 